\title{
Revisiting the Stability of endo/exo Diels-Alder Adducts between Cyclopentadiene and 1,4-benzoquinone
}

\author{
Claudio F. Tormena, ${ }^{a}$ Valdemar Lacerda Jr. ${ }^{b}$ and Kleber T. de Oliveira ${ }^{*, c}$ \\ ${ }^{a}$ Departamento de Química Orgânica, Instituto de Química, Universidade de Campinas - \\ UNICAMP - CP 6154, 13083-970 Campinas-SP, Brazil
}

${ }^{b}$ Departamento de Química, Centro de Ciências Exatas da Universidade Federal do Espírito Santo UFES, Av. Fernando Ferrari 514, 29060-900 Vitória-ES, Brazil

${ }^{c}$ Centro de Ciências Naturais e Humanas, Universidade Federal do ABC UFABC, Rua Santa Adélia 166, Bangu, 09210-170 Santo André-SP, Brazil

\begin{abstract}
Neste trabalho é apresentada uma análise teórica detalhada da estabilidade relativa dos adutos endolexo formados entre o ciclopentadieno (1) e a 1,4-benzoquinona (2). As coordenadas intrínsecas de reação (IRC) indicaram a presença de apenas um estado de transição para a reação, mostrando que se trata de um mecanismo concertado para ambos os adutos, endo 3 e exo 4 . As energias dos adutos foram calculadas com um alto nível de teoria (CBS-Q) confirmando que o aduto endo é mais estável que o exo, o que está em desacordo com o que é observado para reações que usualmente seguem a regra de Alder. Uma análise estrutural eletrônica foi realizada através da metodologia NBO, a qual indicou que interações atrativas predominam sobre as interações estéricas repulsivas no aduto endo. Em resumo, para a reação de cicloadição estudada o aduto endo é o produto termodinâmico e cinético, o que pode ser confirmado também pelos dados experimentais mencionados neste trabalho.
\end{abstract}

In this work it is presented a detailed theoretical analysis of the relative stability of endo/exo Diels-Alder adducts formed by the reaction between cyclopentadiene (1) and 1,4-benzoquinone (2). The intrinsic reaction coordinate (IRC) showed the existence of only one transition state for the reaction studied, for both endo $\mathbf{3}$ and exo $\mathbf{4}$ adducts. The energies of both adducts were obtained at high level of theory (CBS-Q) confirming that the endo adduct is more stable than exo, which is in the opposite way to the observed in reactions that usually follow Alder's rule. An electronic structure analysis was performed through NBO methodology, indicating that the attractive delocalization interaction predominates over the steric repulsive interaction in the endo adducts. In summary, for the studied cycloaddition reaction the endo adduct is the thermodynamic and kinetic product, which can be also confirmed by experimental data mentioned in this work.

Keywords: Diels-Alder reaction, endo/exo stability, theoretical calculation, NBO analysis

\section{Introduction}

The Diels-Alder reaction is one of the most interesting and useful reactions found in organic chemistry in $20^{\text {th }}$ century. ${ }^{1-8}$ This cycloaddition is widely used to construct, in a regio- and stereo-controlled way, a six-membered ring with up to four stereogenic centers. ${ }^{1-8}$ Historically, in 1906 Albrecht $^{9}$ published the reaction between the cyclopentadiene (1) and 1,4-benzoquinone (2) as a 1:1 adduct. However, Albrecht's considerations about the

*e-mail: kleber.oliveira@ufabc.edu.br structure of the obtained adduct were inconsistent. After several studies, in 1928 Otto Diels and Kurt Alder, ${ }^{10}$ established a correct structure for the mono- and bis-adducts formed by the reaction between these compounds through a [4+2] cycloaddition, in opposition to the reactional course suggested by Albrecht: an 1,4-addition of cyclopentadiene (1) into 1,4-benzoquinone (2). Since then, the Diels-Alder reaction has appeared in more than 32,000 papers involving synthetic and theoretical approaches. ${ }^{11}$

In general, Diels-Alder reactions are excellent reactional models for the transition states calculations due to the nature of their mechanism (usually concerted). 
Besides this, the estimation of several chemical properties and reactivities indexes of dienes and dienophiles can be performed with good experimental agreement. ${ }^{12-15}$ An evidence of the importance of this reaction to the development and application of some computational calculations is the large number of published papers involving considerations about the concerted and nonconcerted, synchronous and asynchronous mechanism nature of some Diels-Alder reactions. ${ }^{15-18}$ Most of these studies attempt to explain some experimental results non-consistent with empirical rules or expected results concerning the selectivity. While experimental measurements can provide accurate rate constants for the different reaction pathways, high-level quantum chemical calculations are often necessary to explain the observed phenomena at an electronic level, to predict the substituent effects and also to evaluate steric interactions between the participating species. In this context, advances in the quantum-chemical calculations methodology (e.g., the development of new DFT functional methods) and the improvements of computational power provided the accuracy needed to quantitatively explain experimental observations. Moreover, convenient methods for the analysis of correlated wave functions, as natural bond orbital analysis (NBO), ${ }^{19,20}$ can be used to evaluate the numerous stereoelectronic interactions, ${ }^{21,22}$ including secondary orbital interactions (SOI) ${ }^{23,24}$ These interactions (SOI) were proposed by Woodward and Hoffmann ${ }^{25}$ to rationalize the empirical endo principle of addition (Alder's rule) formulated by Alder and Stein, ${ }^{26-29}$ but they had been object of some criticism. ${ }^{30}$ According to Alder's rule the major stereoisomer in Diels-Alder reactions is the one that is formed by maximum accumulation of double bonds in the transition state (through-space). 26-29,31-34 On the other hand, the endo product is usually less stable than exo.

While the stereoelectronic interactions, involved in the transition state stability, are widely studied in the literature, ${ }^{14,15,35}$ the same attention has not been dedicated to understand the stability of the products. One of the most used examples of the Diels-Alder reaction, which is listed in several Organic Chemistry textbooks, ${ }^{36-38}$ is that between cyclopentadiene (1) and maleic anhydride which, at room temperature, gives only the endo adduct that is then converted at $200^{\circ} \mathrm{C}$ to the thermodynamically more stable exo adduct through a retro Diels-Alder reaction. ${ }^{4}$ According to several authors, ${ }^{39-48,49-52}$ the Diels-Alder reaction between cyclopentadiene (1) and 1,4-benzoquinone (2) (Scheme 1), gives, in a similar way, only the kinetic endo adduct $\mathbf{3}$, although the exo adduct $\mathbf{4}$ has higher stability than the endo adduct 3 due to the steric repulsive interaction present in the endo form. Actually, we observed from the ${ }^{1} \mathrm{H}$ NMR spectrum of the reactional mixture, $98 \%$ of compound 3 and $2 \%$ of compound 4 (Fig. 1).

Thus, in principle, the results for cycloaddition between compounds $\mathbf{1}$ and $\mathbf{2}$ follow the Alder's rule, however some surprising results were observed when an intrinsic reaction coordinate (IRC) and the NBO analysis of the endolexo transition states and products were performed at high level of theory. These results are discussed in the present study.

\section{Materials and Methods}

\section{Chemicals}

All solvents and reagents were purchased from Merck, Acros or Aldrich. The cyclopentadiene (1) was freshly distilled and then used. $p$-Benzoquinone (2) was purified by sublimation in an appropriated apparatus (Aldrich).

Synthesis of endo-tricyclo[6.2.1.0.2,7undeca-4,9-diene3,6-dione (3)

To a solution containing $541 \mathrm{mg}(5.0 \mathrm{mmol})$ in $18 \mathrm{~mL}$ of dry methanol at $-78^{\circ} \mathrm{C}$ under nitrogen atmosphere, was added cyclopentadiene freshly distilled $(344 \mathrm{mg}, 5.2 \mathrm{mmol}$, in $4 \mathrm{~mL}$ of dry methanol) also cooled to $-78^{\circ} \mathrm{C}$. Then, the reaction mixture was allowed to reach $0{ }^{\circ} \mathrm{C}$ (approx. 1h). After that, the solvent was removed under reduced pressure and the product was crystallized by using hexane, yielding the yellow crystals $(854 \mathrm{mg}, 4.9 \mathrm{mmol}, 98 \%)$. mp. $63-65^{\circ} \mathrm{C}$. ${ }^{1} \mathrm{H} \mathrm{NMR}\left(\mathrm{CDCl}_{3}, 400 \mathrm{MHz}\right), \delta$ (ppm) 1.44 (dt, $1 \mathrm{H}, J 8.4 \mathrm{~Hz}$ and $J 1.7 \mathrm{~Hz} ; 1.55(\mathrm{dt}, 1 \mathrm{H}, J 8.4 \mathrm{~Hz}, J 1.7 \mathrm{~Hz}), 3.20-3.26$ (m, 2H), $3.53-3.58(\mathrm{~m}, 2 \mathrm{H}), 6.07$ (t, 2H, J $1.7 \mathrm{~Hz}), 6.58$ (sl, 2H). ${ }^{13} \mathrm{C} \mathrm{NMR} \mathrm{(100} \mathrm{MHz,} \mathrm{CDCl}_{3}$ ), $\delta$ (ppm) 48.3, 48.7 (2 x CH and $\left.1 \times \mathrm{CH}_{2}\right), 135.3,142.0,199.4$.

\section{Computational Details}

All calculations were performed with Gaussian 03 program. ${ }^{53}$ Full geometry optimization for adducts were performed applying HF, B3LYP, ${ }^{54,55}$ MP2 full ${ }^{56,57}$ (full specifies that all electrons are included in a correlation calculation) and CBS- $\mathrm{Q}^{58}$ methods and Dunning's correlation consistent basis set ${ }^{59,60}$ were used. The CBS-Q method was used to solve the major source of error in most $a b$ initio calculations of molecular energies, which is due to truncation of the one-electron basis set, and the mean absolute deviation in electronic energy, using CBS-Q method, is less than $1 \mathrm{kcal} \mathrm{mol}^{-1} .{ }^{58}$

The transition states calculations (TS) and NBO analysis ${ }^{61}$ were performed at the B3LYP/cc-pVTZ level 


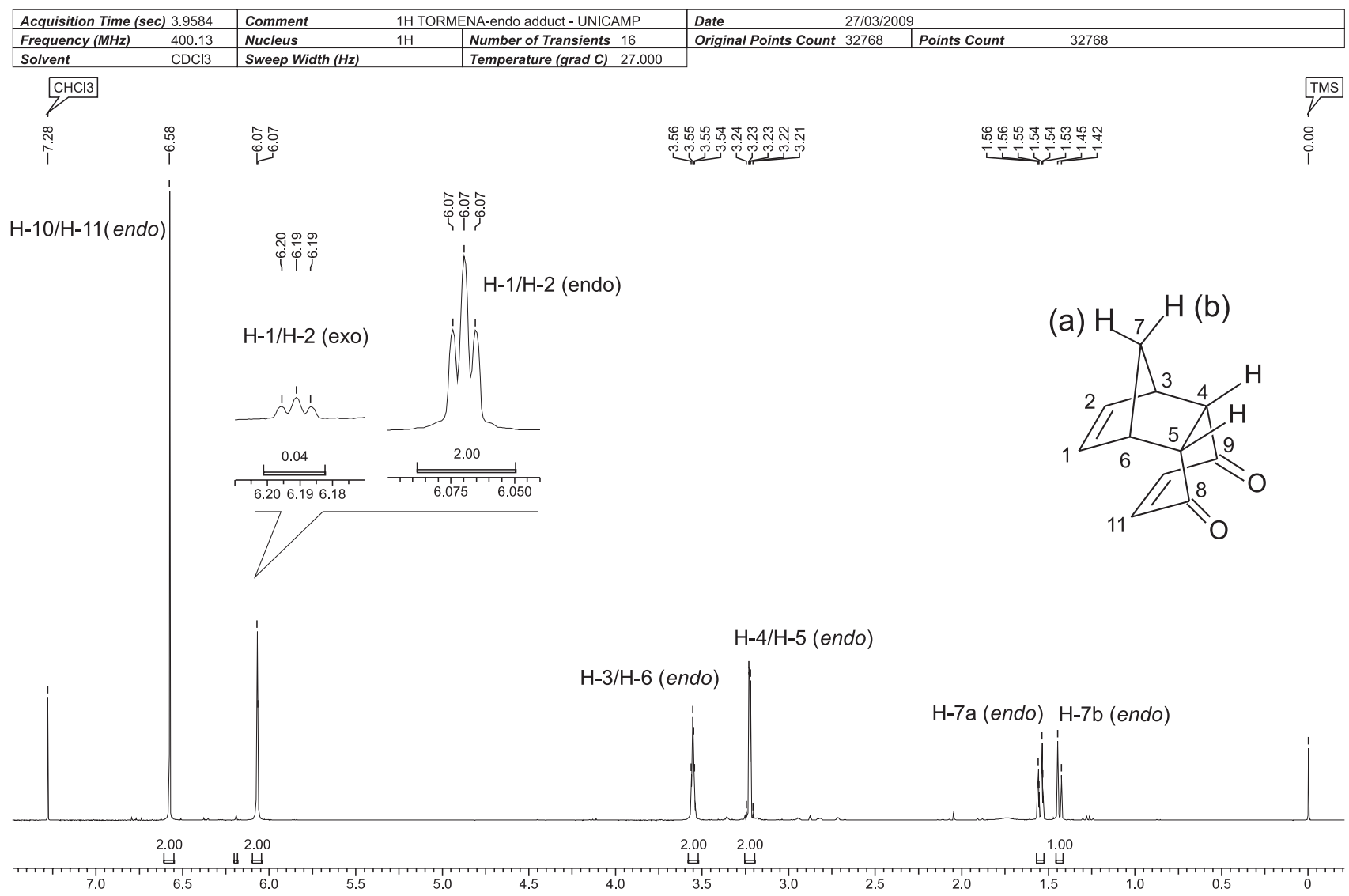

Figure 1. ${ }^{1} \mathrm{H}$ NMR of the obtained products $3(98 \%)$ and $4(2 \%)$.

of theory, while Intrinsic Reaction Coordinate (IRC) calculation was performed at the B3LYP/6-31g (d,p) level. All stationary points were characterized as minima or transition structures by calculating the harmonic vibrational frequencies (ZPE), expected for MP2 full calculations.

\section{Results and Discussion}

The [4+2] cycloaddition between cyclopentadiene (1) and 1,4-benzoquinone (2) can lead to endo and exo products, as shown in Scheme 1.

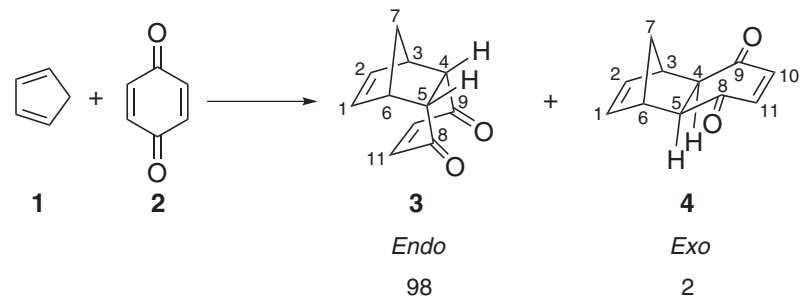

Scheme 1. Diels-Alder reaction between $\mathbf{1}$ and $\mathbf{2}$.

The IRC calculations (Fig. 2) for both reaction pathways were performed at the B3LYP/6-31g $(\mathrm{d}, \mathrm{p})$ level and it was observed that there is only one transition state for both adducts, which suggests that for this reaction the mechanism is concerted. It can also be observed, that the transition state energy to form the endo adduct is smaller than for exo adduct.

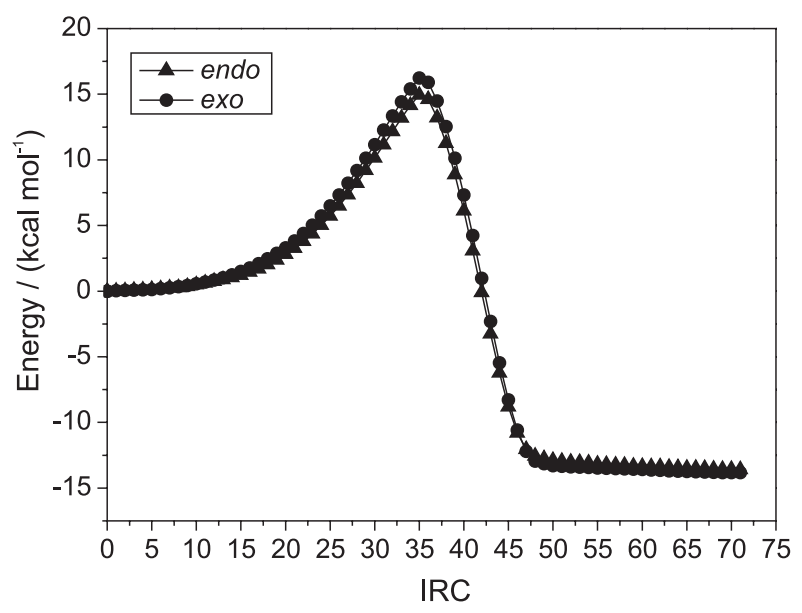

Figure 2. IRC profile for the endo and exo adducts of the [4+2] cyclopentadiene-1,4-benzoquinone cycloaddition.

The geometries and energies for reagents, products and transition state structures were optimized at the B3LYP/ cc-pVTZ level and the energy profiles are shown in Fig. 3. 
It can be observed (Fig. 3) from the theoretical calculation that the energy for exo transition state structure is $1.8 \mathrm{kcal} \mathrm{mol}^{-1}$ higher than for endo (Fig. 4a), which is in agreement with the obtained experimental results (Scheme 1). ${ }^{62}$ However, analyzing the energies of the

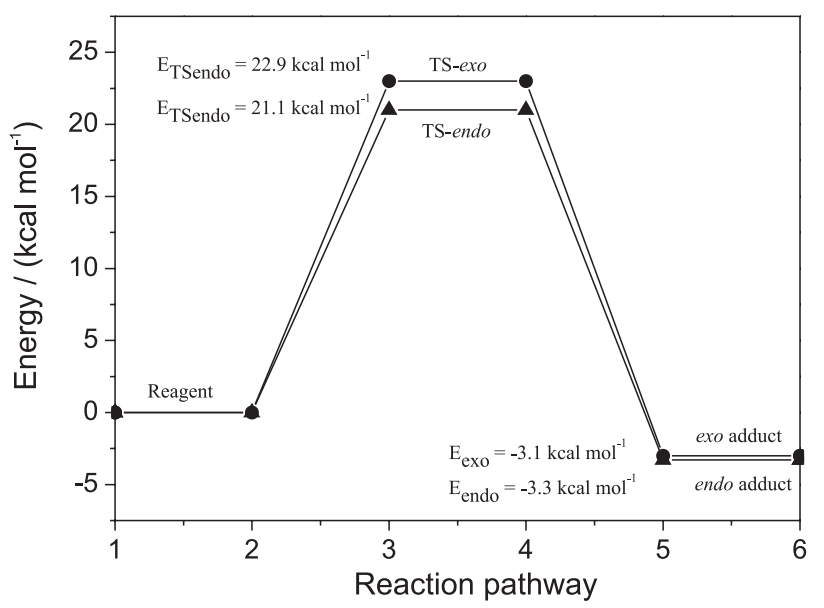

Figure 3. Energies for endo and exo reaction pathways of the [4+2] cycloaddition reaction of cyclopentadiene and 1,4-benzoquinone calculated at the B3LYP/cc-pVTZ level.

a)

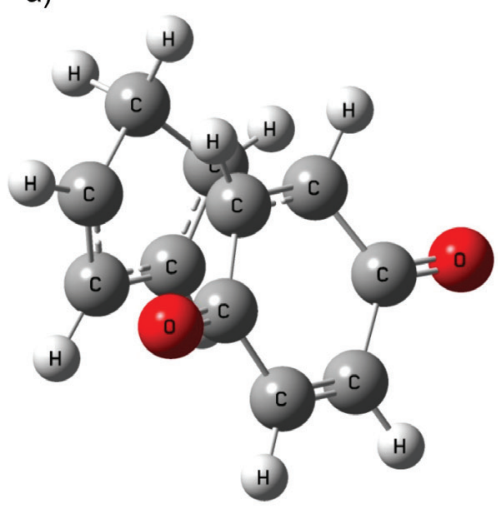

TS-endo

b)

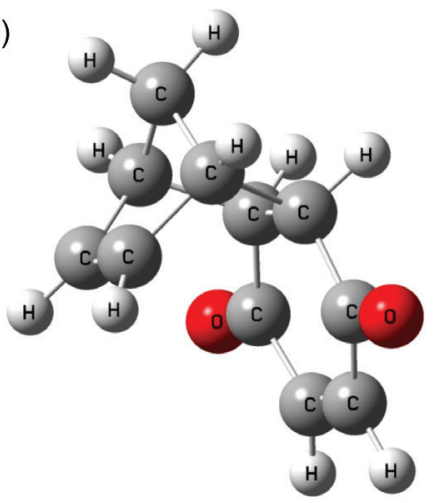

endo 3 products it was observed that the endo adduct (Fig. 4b) is more stable (thermodynamic product) than exo, which is in disagreement with literature data. ${ }^{39-48}$ It is reported in literature ${ }^{39-48}$ that exo is the thermodynamic and endo is the kinetic product.

Theoretical calculations at high level of theory (Table 1) were performed for adducts endo and exo to get more accurate energies values to check if the endo adduct is in fact the thermodynamic product. It can be seen from Table 1 that in all levels of theory applied in the present study, the endo adduct is the more stable than exo.

Table 1. Calculated energies $\left(\mathrm{kcal} \mathrm{mol}^{-1}\right)$ for adducts endo and exo at different level of theory

\begin{tabular}{llccc}
\hline Method & Basis set & $\mathrm{E}_{\text {endo }}$ & $\mathrm{E}_{e x o}$ & $\Delta \mathrm{H}$ \\
\hline HF & cc-pVTZ & 0.0 & 0.9 & 0.9 \\
HF & aug-cc-pVTZ & 0.0 & 0.9 & 0.9 \\
B3LYP & cc-pVTZ & 0.0 & 0.2 & 0.2 \\
B3LYP & aug-cc-pVTZ & 0.0 & 0.3 & 0.3 \\
MP2 full & cc-pVDZ & 0.0 & 1.1 & - \\
CBS-Q & & 0.0 & 1.1 & 1.1 \\
\hline
\end{tabular}

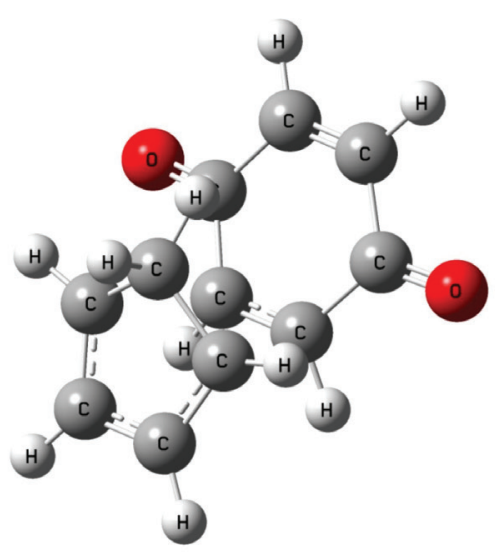

TS-exo

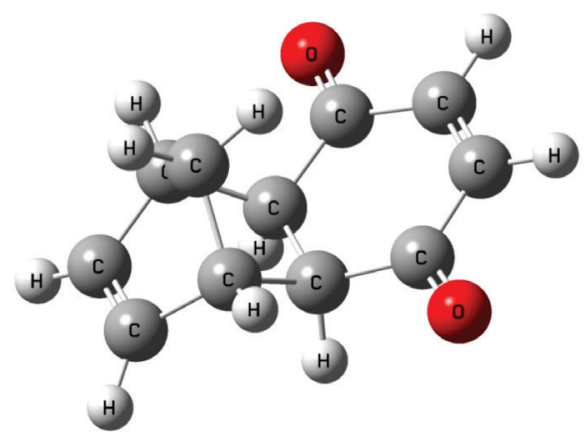

exo 4

Figure 4. Optimized structures for: a) transition states; b) products. 
Table 2. Energies obtained from NBO deletion calculation for endo and exo adducts at the HF and B3LYP method using cc-pVTZ basis set

\begin{tabular}{|c|c|c|c|c|}
\hline \multirow[t]{2}{*}{ Parameters } & \multicolumn{2}{|c|}{ HF/cc-pVTZ } & \multicolumn{2}{|c|}{ B3LYP/cc-pVTZ } \\
\hline & endo & exo & endo & exo \\
\hline Total SCF energy (a.u) & -572.244626 & -572.243196 & -575.778572 & -575.778335 \\
\hline Deletion energy (a.u) & -571.131031 & -571.137107 & -574.731736 & -574.736773 \\
\hline Energy change $(\mathrm{a} . \mathrm{u})^{\mathrm{a}}$ & 1.113595 & 1.106089 & 1.046836 & 1.041562 \\
\hline$\Delta \mathrm{E}\left(\mathrm{kcal} \mathrm{mol}^{-1}\right)^{\mathrm{b}}$ & 4.7 & 0.0 & 3.3 & 0.0 \\
\hline
\end{tabular}

${ }^{\mathrm{a}}$ Energy change $=$ Total SCF energy - Deletion energy. ${ }^{\mathrm{b}} \Delta \mathrm{E}=$ energy change for endo - energy change for exo.

Structure stability is usually explained by stereoeletronic interactions [attractive (delocalization interaction) or repulsive (steric interaction)]. ${ }^{63,64}$ The NBO analyses can be invoked to explain the unexpected stability observed for endo adduct and quantify the delocalization interaction. There is a simple way to determine which interaction (attractive or repulsive) is more pronounced in any structure. First the NBO analysis of a full wave function was performed. Then, only the attractive delocalization interactions are deleted (NBOdel) and the energy is recalculated without these delocalization interactions, which means that only steric interactions will be present. The energy change values (Table 2) can be used to determine the amount of attractive or repulsive interactions in endo and exo adducts. This energy value is the difference between a full molecular electronic energy and the molecular electronic energy calculated deleting the delocalization interactions, and the larger is this energy change the large attractive delocalization interaction the structure has.

When these energy changes for endo and exo are computed (Table 2) at the HF/cc-pVTZ and B3LYP/ cc-pVTZ level, deleting the delocalization interactions (NBOdel), the exo adduct becomes more stable than endo by 4.7 and $3.3 \mathrm{kcal} \mathrm{mol}^{-1}$, respectively. The data from Table 2 corroborate that in the endo adduct the steric repulsive interactions are larger than in exo, however, the attractive delocalization interaction in endo is higher than in exo and compensates the steric repulsion. This is the reason why the endo $\mathbf{3}$ is also the thermodynamic product and not the exo 4, as it is reported in the current literature.

The most important delocalization orbital interactions from NBO analysis involving bonding and antibonding orbital, responsible for the stabilization of endo adduct, are listed in Table 3; similar interactions for exo adduct were also collected. The interactions listed at Table 3, are those only for the molecular fragment that differentiate endo from the exo adduct. As can be seen from Table 3, the attractive interactions (delocalization orbital interactions) are higher for endo than exo adduct, and probably are responsible for extra stabilization acquired for endo in comparison to exo. Probably, other interactions involving
Table 3. Delocalization orbital interaction energies $\left(\mathrm{kcal} \mathrm{mol}^{-1}\right)$ from NBO analysis for endo and exo adduct, calculated at the HF/cc-pVTZ level

\begin{tabular}{lcc}
\hline Orbital interaction & endo & exo \\
\hline$\pi_{\mathrm{C} 1=\mathrm{C} 2} \rightarrow \sigma_{\mathrm{C} 5-\mathrm{C} 6}^{*}$ & 4.6 & 4.3 \\
$\pi_{\mathrm{C} 1=\mathrm{C} 2} \rightarrow \sigma_{\mathrm{C} 5-\mathrm{H} 9}^{*}$ & 1.3 & 0 \\
$\sigma_{\mathrm{C} 4-\mathrm{C} 5} \rightarrow \sigma_{\mathrm{C} 8=\mathrm{O}}^{*}$ & 3.3 & 3.3 \\
$\sigma_{\mathrm{C} 5-\mathrm{C} 8} \rightarrow \sigma_{\mathrm{C} 6-\mathrm{C} 7}^{*}$ & 1.5 & 0 \\
$\sigma_{\mathrm{C} 5-\mathrm{H} 9} \rightarrow \sigma_{\mathrm{C} 6-\mathrm{C} 1}^{*}$ & 3.3 & 2.0 \\
$\sigma_{\mathrm{C} 5-\mathrm{H} 9} \rightarrow \pi_{\mathrm{C} 8=\mathrm{O}}^{*}$ & 8.2 & 7.8 \\
$\sigma_{\mathrm{C} 6-\mathrm{C} 7} \rightarrow \sigma_{\mathrm{C} 5-\mathrm{C} 8}^{*}$ & 4.8 & 3.1 \\
$\sigma_{\mathrm{C} 5-\mathrm{C} 6} \rightarrow \pi_{\mathrm{C} 8=\mathrm{O}}^{*}$ & 2.9 & 3.3 \\
$\mathrm{Sum}$ & 29.9 & 23.8 \\
\hline
\end{tabular}

other parts of molecule system should also increase the stabilization of endo.

The results discussed in the present paper can be used for a correct explanation of the experimental results obtained by Yates and $\mathrm{Switlak}^{48}$ for thermal stereoisomerization of adduct endo 3 . In their study ${ }^{48}$ the authors reflux a solution of adduct endo in toluene under argon for $36 \mathrm{~h}$ and the products of this thermal isomerization consisted of 1:9 mixture of adduct exo and endo (50\%), one hydroquinone derivative (1,4-dihydro-1,4-methanonaphthalene-5,8-diol) and 1,4-benzoquinone. The authors suggest that the small amount of exo adduct is due to the position equilibrium was not established under that conditions. However, the reason for small amount of exo adduct obtained in the thermo stereoisomeration reaction performed by Yates and Switlak ${ }^{48}$ is simply due to the fact that the endo adduct is the thermodynamic and also the kinetic product.

\section{Conclusions}

The study described in the present work was performed at high level of theory using sophisticated theoretical methods and shows some evidences that the oldest Diels-Alder reaction follow Alder rule. However, the adduct endo $\mathbf{3}$ is not only the kinetic product, but also the thermodynamic product, which is in agreement with 
experimental data. Also, this study demonstrates that some stabilizing stereoeletronic interactions are present in the endo product similar to observed in the endo transition state.

The most important point that we want to emphasize is that the stability acquired by any structure will depend of an energy balance between attractive and repulsive interactions present in that structure.

\section{Acknowledgments}

The authors thank the Fundação de Amparo à Pesquisa do Estado de São Paulo (FAPESP) for financial support for this research (05/59649-0 and 06/03980-2), for postdoctoral scholarship (07/03589-4) and for financial support (2008/06619-4) of K.T.O. Thanks are also due to the Prof. Y. Iamammoto, Prof. O. A. Serra and Prof. R. Rittner Neto by the scientific contributions.

\section{References}

1. Takao, K.; Munakata, R.; Tadano, K.; Chem Rev. 2005, 105, 4779.

2. Nicolaou, K. C.; Snyder, S.A.; Montagnon, T.; Vassilikogiannakis, G.; Angew. Chem., Int. Ed. 2002, 41, 1668.

3. Corey, E. J.; Angew. Chem., Int. Ed. 2002, 41, 1650.

4. Fringuelli, F.; Taticchi, A.; The Diels-Alder Reaction: Selected Practical Methods, John Wiley \& Sons: New York, 2002.

5. Brocksom, T. J.; Nakamura, J.; Ferreira, M. L.; Brocksom, U.; J. Braz. Chem. Soc. 2001, 12, 597.

6. Dias, L. C.; J. Braz. Chem. Soc. 1997, 8, 289.

7. Sauer, J.; Sustmann, R.; Angew. Chem., Int. Ed. 1980, 19, 779.

8. Norton, J. A.; Chem. Rev. 1942, 31, 319.

9. Albrecht, W.; Lieb. Ann. Chem. 1906, 31, 348.

10. Diels, O.; Alder, K.; Lieb. Ann. Chem. 1928, 460, 98.

11. Scifinder Scholar Software version 2006 in December, 2008.

12. Gordillo, R.; Houk, K. N.; J. Am. Chem. Soc. 2006, 128, 3543.

13. Pieniazek, S. N.; Houk, K. N.; Angew. Chem., Int. Ed. 2006, $45,1442$.

14. Afarinkia, K.; Bearpark, M. J.; Ndibwami, A.; J. Org. Chem. 2003, 68, 7158 .

15. Domingo, L. R.; Aurell, M. J.; Contreras, R.; J. Org. Chem. 2003, 68, 3884.

16. Chen, J. S.; Houk, K. N.; Foote, C. S.; J. Am. Chem. Soc. 1998 , 120, 12303.

17. Goldstein, E.; Beno, B.; Houk, K. N.; J. Am. Chem. Soc. 1996, 118, 6036.

18. Houk, K. N.; Li, Y.; Evanseck, J. D.; Angew. Chem., Int. Ed. 1992, 31, 682 .

19. Reed, A. E.; Curtiss, L. A.; Weinhold, F.; Chem. Rev. 1988, 88, 899.
20. Carpenter, J. E.; Weinhold, F.; J. Mol. Struct. (THEOCHEM) 1988, 46, 41.

21. Caramori, G. F.; de Oliveira, K. T.; Galembeck, S. E.; Bultinck, P.; Constantino, M. G.; J. Org. Chem. 2007, 72, 76.

22. Caramori, G. F.; Galembeck, S. E.; J. Phys. Chem. A 2007, 111, 1705.

23. Arrieta, A.; Cossío, F. P.; Lecea, B.; J. Org. Chem. 2001, 66, 6178.

24. Wannere, C. S.; Paul, A.; Herges, R.; Houk, K. N.; Schaefer III, H. F.; Schleyer, P. V. R.; J. Comput. Chem. 2007, 28, 344.

25. Hoffmann, R.; Woodward, R. B.; J. Am. Chem. Soc. 1965, 87, 4388.

26. Alder, K.; Stein, G.; von Budedenbrock, F.; Eckardt, W.; Frercks, W.; Schneider, S.; Lieb. Ann. Chem. 1934, 514, 1.

27. Alder, K.; Stein, G.; Liebmann, M.; Rolland, E.; Lieb. Ann. Chem. 1934, 514, 197.

28. Alder, K.; Stein, G.; Rolland, E.; Schulze, G.; Lieb. Ann. Chem. 1934, 514, 211.

29. Alder, K.; Stein, G.; Angew. Chem., Int. Ed. 1937, 50, 510.

30. García, J. I.; Mayoral, J. A.; Salvatella, L.; Acc. Chem. Res. 2000, 33, 658.

31. Carey, F. A.; Sundberg, R. J.; In Advanced Organic Chemistry. Part A and B: Structure and Mechanisms; $4^{\text {th }}$ ed., Plenum Press: New York, 2001, ch 6.

32. Smith, M. B.; March, J.; Advanced Organic ChemistryReaction, Mechanisms and Structure; $5^{\text {th }}$ ed.; Wiley: New York, 2001.

33. Vollhardt, K. P. C.; Schore, N. E.; Organic Chemistry-Structure and Function, $3^{\text {rd }}$ ed., W.H. Freeman: New York, 1999.

34. Lowry, T. H.; Richardson, K. S.; Mechanism and Theory in Organic Chemistry, $3^{\text {rd }}$ ed., Harper Collins: New York, 1987.

35. Alves, C. N.; Carneiro, A. S.; Andrés, J.; Domingo, L. R. Tetrahedron 2006, 62, 5502.

36. Clayden, J.; Greeves, N.; Warren, S.; Wothers, P.; Organic Chemistry, $1^{\text {th }}$ ed., Oxford University Press Inc.: New York, 2001.

37. McMurry J.; Organic Chemistry, $5^{\text {th }}$ ed., Brooks Cole: New York, 2000.

38. Solomons, T. W. G. Organic Chemistry, $6^{\text {th }}$ ed., John Wiley Sons: New York, 1996.

39. Wassermann, A.; J. Chem. Soc. 1935, 828.

40. Wassermann, A.; J. Chem. Soc. 1935, 1511.

41. Wassermann, A.; J. Chem. Soc. 1936, 432.

42. Wassermann, A.; Nature 1936, 368.

43. Butz, L. W.; Rytina, A. W.; Org. React. 1948, 5, 136.

44. Alder, K.; Flock, F. H.; Beumling, H.; Chem. Ber. 1960, 93, 1896.

45. Tyutylkov, N.; Markov, P.; Monatsh. Chem. 1965, 96, 2030.

46. Oda, M.; Kawase, T.; Okada, T.; Enomoto, T.; Org. Synth. Coll. 1998, 9, 186.

47. Stoermer, M. J.; Butler, D. N.; Warrener, R. N.; Weerasuria, K. D. V.; Fairlie, D. P.; Chem. --Eur. J. 2003, 9, 2068. 
48. Yates, P.; Switlak, K.; Can. J. Chem. 1990, 68, 1894.

49. Mehta, G.; Islam, K.; Org. Lett. 2004, 6, 807.

50. Mehta, G.; Islam, K.; Tetrahedron Lett. 2003, 44, 3569.

51. Tanaka, H.; Kamikubo, T.; Yoshida, N.; Sakagami, H.; Taniguchi, T.; Ogasawara, K.; Org. Lett. 2001, 3, 679.

52. Constantino, M. G.; Beatriz, A.; da Silva, G. V. J.; Tetrahedron Lett. 2000, 41, 7001 .

53. Frisch, M. J.; Trucks, G. W.; Schlegel, H. B.; Scuseria, G. E.; Robb, M. A.; Cheeseman, J. R.; Montgomery, J. A.; Vreven, T.; Kudin, K. N.; Burant, J. C.; Millam, J. M.; Iyengar, S.; Tomasi, J.; Barone, V.; Mennucci, B.; Cossi, M.; Scalmani, G.; Rega, N.; Petersson, G. A.; Nakatsuji, H.; Hada, M.; Ehara, M.; Toyota, K.; Fukuda, R.; Hasegawa, J.; Ishida, M.; Nakajima, T.; Honda, Y.; Kitao, O.; Nakai, H.; Klene, M.; Li, X.; Knox, J. E.; Hratchian, H. P.; Cross, J. B.; Bakken, V.; Adamo, C.; Jaramillo, J.; Gomperts, R.; Stratmann, R. E.; Yazyev, O.; Austin, A. J.; Cammi, R.; Pomelli, C.; Ochterski, J. W.; Ayala, P. Y.; Morokuma, K.; Voth, G. A.; Salvador, P.; Dannenberg, J. J.; Zakrzewski, V. G.; Dapprich, S.; Daniels, A. D.; Strain, M. C.; Farkas, O.; Malick, D. K.; Rabuck, A. D.; Raghavachari, K.; Foresman, J. B.; Ortiz, J. V.; Cui, Q.; Baboul, A. G.; Clifford, S.; Cioslowski, J.; Stefanov, B. B.; Liu, G.; Liashenko, A.; Piskorz, P.; Komaromi, I.; Martin, R. L.; Fox, D. J.; Keith, T.; Al-Laham, M. A.; Peng, C. Y.; Nanayakkara, A.; Challacombe, M.; Gill, P. M. W.; Johnson, B.; Chen, W.; Wong, M. W.; Gonzalez, C.; Pople, J. A., Gaussian 03, Revision E.01, Gaussian, Wallingford CT, 2004
54. Becke, A. D.; J. Chem. Phys. 1993, 98, 5648

55. Lee, C. T.; Yang, W. T.; Parr, R. G.; Phys. Rev. B 1988, 37, 785.

56. Moller, C.; Plesset, M. S.; Phys. Rev. 1934, 46, 618.

57. Head-Gordon, M.; Pople, J. A.; Frisch, M. J.; Chem. Phys. Lett. 1988, 155, 503.

58. Ochterski, J. W.; Petersson, G. A.; Montgomery Jr., J. A.; J. Chem. Phys. 1996, 104, 2598.

59. Dunning Jr., T. H.; J. Chem. Phys. 1989, 90, 2.

60. Peterson, K. A.; Woon, D. E.; Dunning Jr., T. H.; J. Chem. Phys. 1994, 100, 10

61. Glendening, E. D.; Badenhoop, J. K.; Reed, A. E.; Carpenter, J. E.; Bohmann, J. A.; Morales, C. M.; Weinhold, F.; NBO 5.G. software, http://www.chem.wisc.edu/ nbo5 (Theoretical Chemistry Institute, University of Wisconsin, Madison, WI, USA, 2001).

62. Marchand, A. P.; Allen, R. W.; J. Org. Chem. 1974, 39, 1596.

63. Lahiri, S.; Yadav, S.; Banerjee, S.; Patil, M. P.; Sunoj, R. B.; J. Org. Chem. 2008, 73, 435.

64. Bakalova, S. M.; Santos, A. G.; J. Org. Chem. 2004, 69, 8475.

Received: January 8, 2009

Web Release Date: October 23, 2009

FAPESP helped in meeting the publication costs of this article. 